Sharif University of Technology
Scientia Iranica
SCIENTIA
I RAN I C A

\title{
Investigating the experimental behavior of the reinforcements effect on the railway traverse under the dynamic load
}

\author{
A. HajianiBoushehrian ${ }^{\mathrm{a}, *}$, A. Vafamand ${ }^{\mathrm{b}}$ and S. Kohan ${ }^{\mathrm{a}}$ \\ a. Department of Civil Engineering, Shiraz Branch, Islamic Azad University, Shiraz, Iran. \\ b. Department of Civil Engineering, Estahban Branch, Islamic Azad University, Estahban, Iran. \\ Received 2 October 2015; received in revised form 19 April 2016; accepted 29 August 2016
}

\author{
KEYWORDS \\ Traverse; \\ Dynamic load; \\ Static load; \\ Geogrid; \\ Settlement; \\ Grid-Anchor.
}

\begin{abstract}
An investigation into the causes of settlement and its control can place an obstacle to such hazards as derailing of a train due to the railway settlement. In this study, the effect of both geogrid and geogrid anchor concerning the railway ballast layer settlement reduction has been taken into account. For this purpose, the ballast performance in the field conditions was simulated using a small-scale box test. In this experiment, the static load was considered as the sum of the train and passenger weight and the dynamic load related to the train vibration. Since this research aims at launching an investigation into the influence of utilizing geogrids in order to reduce the ballast settlement, this experiment was carried out by considering the geogrid and geogrid anchor layer, the loading frequency variation, the amount of loading, the geogrid position, the number of geogrid layers, and the related distances. Also, the results obtained from the empirical model have been analyzed and compared. A number of relations based upon the test results have been developed to estimate the permanent settlement relative to the dynamic load and the number of reinforcement layers.

(C) 2017 Sharif University of Technology. All rights reserved.
\end{abstract}

\section{Introduction}

The network infrastructures include roads and railroads. Using soil and rock materials as infrastructure and ultrastructure layers in this network is inevitable. Today, increasing the traffic volume and the network ground load involves building road-rail lines and highspeed ways. In recent years, studies have been done on the foundation in the presence and absence of the reinforcements under the cyclic load. Yeo et al. (1993) showed that the maximum settlement depends

\footnotetext{
*. Corresponding author.

E-mailaddress: ahajiani@gmail.com (A.

HajianiBoushehrian)
}

doi: $10.24200 /$ sci. 2017.4149 on the cyclic loads, dynamic load amplitude, static load amplitude $\left(q_{s}\right)$, stiffness, and soil density [1]. Das and Shin (1994) indicated that the laboratory model of the permanent settlement is increased by increasing the number of cycles $\left(n_{c r}\right)$ and $q_{s}$. They also found that increasing the depth can reduce the foundation permanent settlement by about $20 \%$ to $30 \%$ [2]. Das and Shin (1996) revealed that the rapid settlement of the strip foundation due to cyclic load application takes place during the ten cycles of loading, constituting about $60 \%$ to $80 \%$ of the total settlement [3]. Ling et al. (2001) investigated the performance of asphalt pavement under the dynamic and cyclic conditions [4]. They observed that the recorded strain level in the polypropylene for the cyclic load experiment is less than the experiments with constant load. Nazzal et al. (2007) conducted that the most effective reinforcement 
in the broken limestone materials under cyclic and monotonic loading was observed in the presence of the two-layer geogrid at the distance equal to 0.33 times of the foundation width [5].

Such studies on the train load were conducted by Claus and Ulrike (1994) [6]. They showed that the reinforcing the sub-base layer increases the bearing capacity to almost $70 \%$ in contrast with the unreinforced condition. Das et al. (2002) showed that the most effective state in reducing the permanent settlement on the rail bed is the geogrid and geotextile layers on the surfaces of the roadbed [7]. Brown et al. (2007) showed that the reinforcement affects the soft subgrade more compared to the stiff one [8].

Recent research on the storage tank foundations with frequent discharges and cyclic loading with the amplitude well below their allowable bearing capacity was done by Bosusherian et al. (2010) [9]. They showed that over half of the settlement is observed in the early cycles of loading. By increasing the loading cycles, the soil becomes more compact; therefore, the settlement is reduced by interlocking the soil grains further with the reinforcements.

Tafreshi et al. conducted some studies on small-scale model foundation under the repeated loads $[10,11]$. They investigated the vehicle load effects in the laboratory tests on the small-diameter highdensity polyethylene (HDPE) pipes. The deformation produced at the first cycle was significantly more than the next cycles. The soil reinforcement leading to the increased resistance reduced the volume changes, thereby providing the specific behavior in the soil. More studies have investigated the reinforcement field conditions under the static load rather than dynamic or transient one [12] (e.g. [13-15). Bushehrian and Hataf (2008) observed that the greatest effect of the reinforcement occurs when the reinforcements in the circular and ring foundations in the layers are placed close to each other [16]. Patra et al. (2005) showed that the ultimate bearing capacity increases by increasing embedment ratio, $d_{f} / B$, in which $d_{f}$ is foundation depth [17].

Also, in 2006, efforts made by Patra et al. led to an empirical relationship between the buried depth, the eccentric load, and bearing capacity of the strip foundation rested on geogrid-reinforced sand [18].

Sitharam and Sireesh (2006) showed that geocell layers below the geogrid increase the bearing capacity and the foundation stiffness [19]. Some types of reinforcement are made of recycling environmental materials, or they are produced by researchers. Won Yoon and Seong Kang (2004) used the tire shreds in the sand [20], and Bushehrian et al. (2010) [21] employed the grid anchor designed and made by Mosallanezhad [22]. Chirist (2003) examined soil behavior under repeat loading by means of experimental investigation and static analysis [23]. MoghaddasTafreshi and Dawson (2010) showed that preparing and reinforcing the sand layer with 3D reinforcement in the same mass and characteristics can significantly reduce the foundation settlement as compared with the 2D geotextile [24]. MoghaddasTafresi et al. performed a series of cyclic load tests examined on circular plate with diameter of $300 \mathrm{~mm}$ on different layers of geocell [25]. They showed that geocell layers had significant effect on reducing stress under the shallow foundation. In comparison to the unreinforced condition, the pressure at the depth of $350 \mathrm{~mm}$ was reduced to $30.40 \%$ and $40.70 \%$ for one and two layers of geocell, respectively.

The current work has been done to investigate the settlement parameters on traverse under the railway loads. After the simulation of the train load with the device made in advanced soil mechanics laboratory of Shiraz Islamic Azad University, the behavior of the reinforcement effects was studied on the railway traverse under dynamic loading. At last, based on the results, the equations were provided for the reinforced sleeper under the static and dynamic loads to predict the permanent settlement of the types and the number of reinforcement layers, the loading amplitude, and the loading frequency.

\section{Materials}

Distribution curve for sand and ballast materials is shown in Figure 1. The soil parameters are presented in Table 1. The ballast thickness is under the main lines and must not be selected less than $30 \mathrm{~cm}$ based on the standard soil classifications [26]. Also, to maintain the stability of the ballast, the thickness under the traverse must not exceed $50 \mathrm{~cm}$. Based on these two limitations, the ballast thickness has been considered $35 \mathrm{~cm}$. The geogrid reinforcement type used in the tests was Nelton-Ce131 hexagonal grid with the technical specifications in accordance with the Table 2.

The grid-anchor used for the test program was a 3dimensional reinforcement system. This reinforcement was made of additional anchors at an angle of $45^{\circ}$ with plastic belts. The ends were made of two polymer cubes

Table 1. Soil parameters.

\begin{tabular}{cccccc}
\hline USCS & $\boldsymbol{D}_{\mathbf{1 0}}$ & $\boldsymbol{D}_{\mathbf{3 0}}$ & $\boldsymbol{D}_{\mathbf{6 0}}$ & $\boldsymbol{C}_{\boldsymbol{C}}$ & $\boldsymbol{C}_{\boldsymbol{U}}$ \\
\hline $\mathrm{SM}$ & 0.004 & 0.071 & 0.649 & 2.17 & $\mathbf{1 7 9 . 8 4}$
\end{tabular}

Table 2. Properties of reinforcement.

\begin{tabular}{ccc}
\hline Parameter & Unite & Value \\
\hline Elastic axial stiffness & $\mathrm{kN} / \mathrm{m}$ & 11.7 \\
Geogrid opening size & $\mathrm{mm}$ & $27 \times 27$
\end{tabular}

The average thickness of cross members mm 2.2 


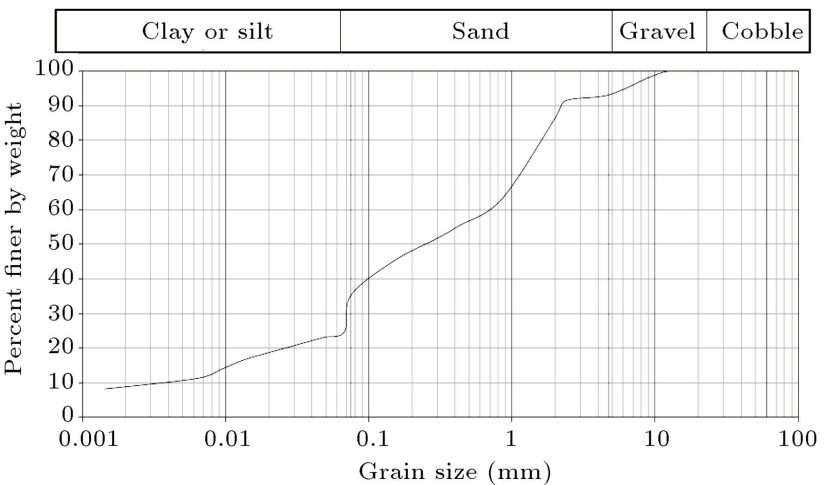

(a)

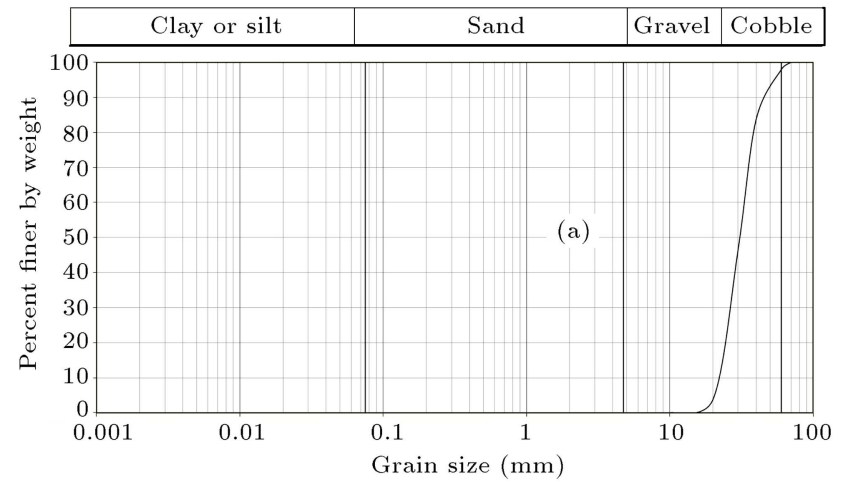

(b)

Figure 1. Grain-size distribution: (a) Grain-size distribution of sand, and (b) grain-size distribution of ballast.

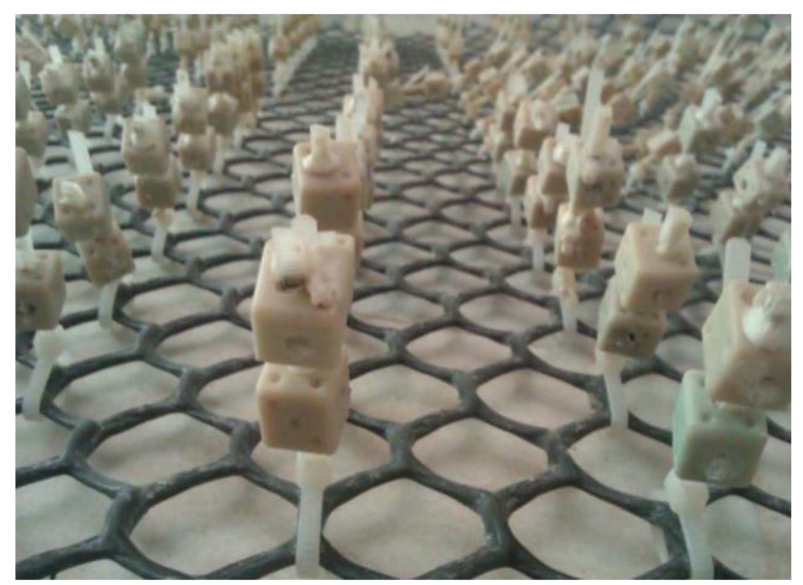

Figure 2. Grid anchor reinforcement.

with the dimensions of $10 \times 10 \times 10 \mathrm{~mm}$ (Figure 2) and arranged according to Figure 3 . The system was used for the first time by Mosallanezhad et al. [22].

\section{Dynamic and static load values to test}

The schematic applied load is shown in Figure 4. The static load values were obtained in accordance with Das and Shin 1994, that is, the maximum load carriage was selected based on 200 ton wagon. This

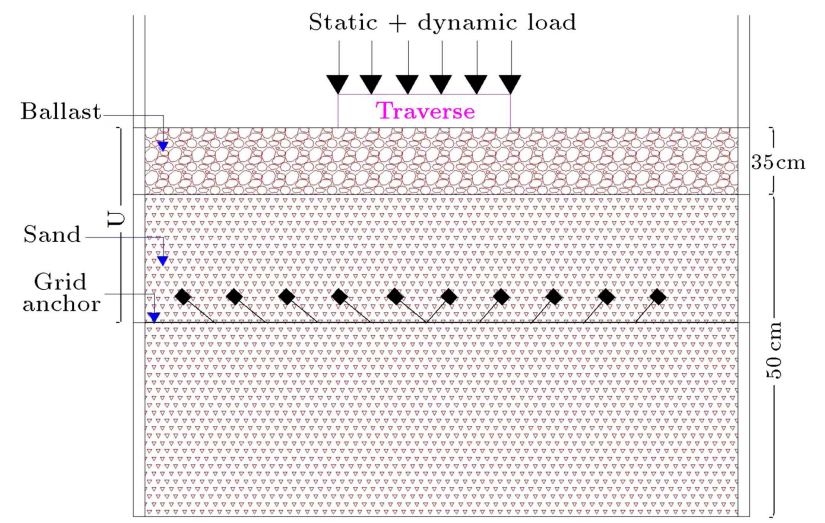

Figure 3. Arrangement of grid anchor reinforcement for the tests.

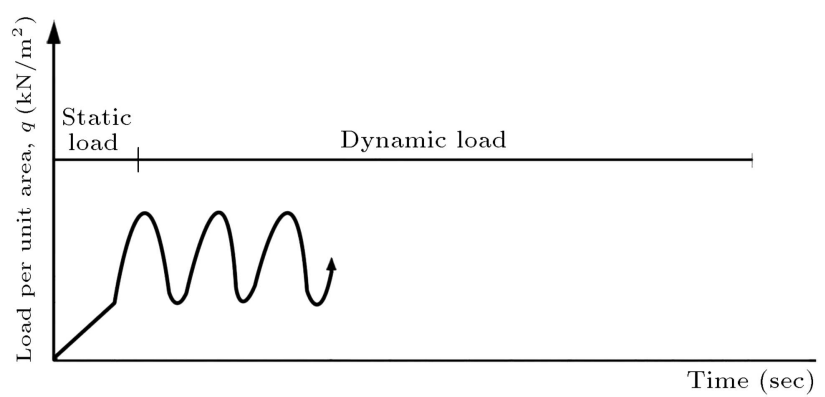

Figure 4. The schematic pattern of cyclic and dynamic loadings.

value $(472 \mathrm{~kg})$ produced $295 \mathrm{kN} / \mathrm{m}^{2}$ stress for each wheel. The dynamic load was added to static load and its intensity was based on the large-scale experiments and laboratory models to simulate the movement of a train equal to $400 \mathrm{~kg}$ dynamic load. This load could produce $250 \mathrm{kN} / \mathrm{m}^{2}$ stress [7]. Considering the effects of overloading, which consist of passengers or the load on railroads, the additional load was $125 \%, 150 \%$, $175 \%$, and $200 \%$ of the specified dynamic load equal to $500,600,700$, and $800 \mathrm{~kg}$, respectively.

\section{Test sample preparation}

The test device can apply the dynamic and static loads separately and simultaneously (Figure 5 ). This device contains a test tank at $1 \times 1 \times 1 \mathrm{~m}$.

At first, the sand was poured into the tank to a height of $50 \mathrm{~cm}$. In order to achieve the desired density, the square hammer was designed and built with dimensions of $30 \times 30 \mathrm{~cm}$ and the height of $20 \mathrm{~cm}$. After placing each layer within the thickness of $5 \mathrm{~cm}$, all parts of the layer were compacted with 5 blows at height of $20 \mathrm{~cm}$. This was repeated again for the next layer. Then, the gravel layers with a thickness of $35 \mathrm{~cm}$ were added to the tank device as the ballast and the LVDT balance leveling performed to tension were equally distributed. To prevent errors in recorded 


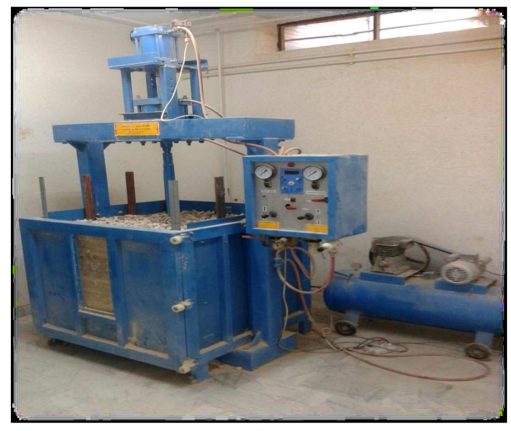

(a)

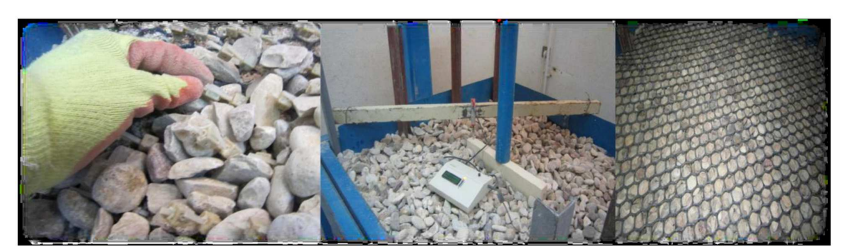

(b)

Figure 5. Static and dynamic load testing devices: (a) Front view, and (b) sample preparation for testing.

data, the LVDT and data logger were connected to the base and placed on the traverse. Then, loading jack was installed in its place. After placing the traverse, the LVDT and data logger were put in their places to record the traverse settlement. By turning on the compressors, the air pressure reached 5 bars and the device started the static loading. Then, the pneumatic system dynamic load was added to the static load at various frequencies.

\section{Test programs}

The tests were carried out by placing the layers of the geogrid and geogrid anchor at 5, 10, 15, and $20 \mathrm{~cm}$ from the traverse bottom (Figure 6). In addition, the tests were repeated for more geogrid layers (up to four layers) and the results were recorded. At the end, an increase of 25 to $200 \%$ of the dynamic load on the model was repeated with different layers and the output results were recorded to consider the reinforced effect on reducing the traverse settlement.

The following equation is considered to show the reinforcement effect:

$$
R_{S T}=\left(\frac{S_{T R}}{S_{T U}}\right) \times 100 .
$$

where:

$R_{S T}: \quad$ Traverse settlement ratio

$S_{T R}: \quad$ Traverse settlement in the presence of reinforcement

$S_{T U}: \quad$ Traverse settlement in the absence of reinforcement

To ensure that there was no device error, 6

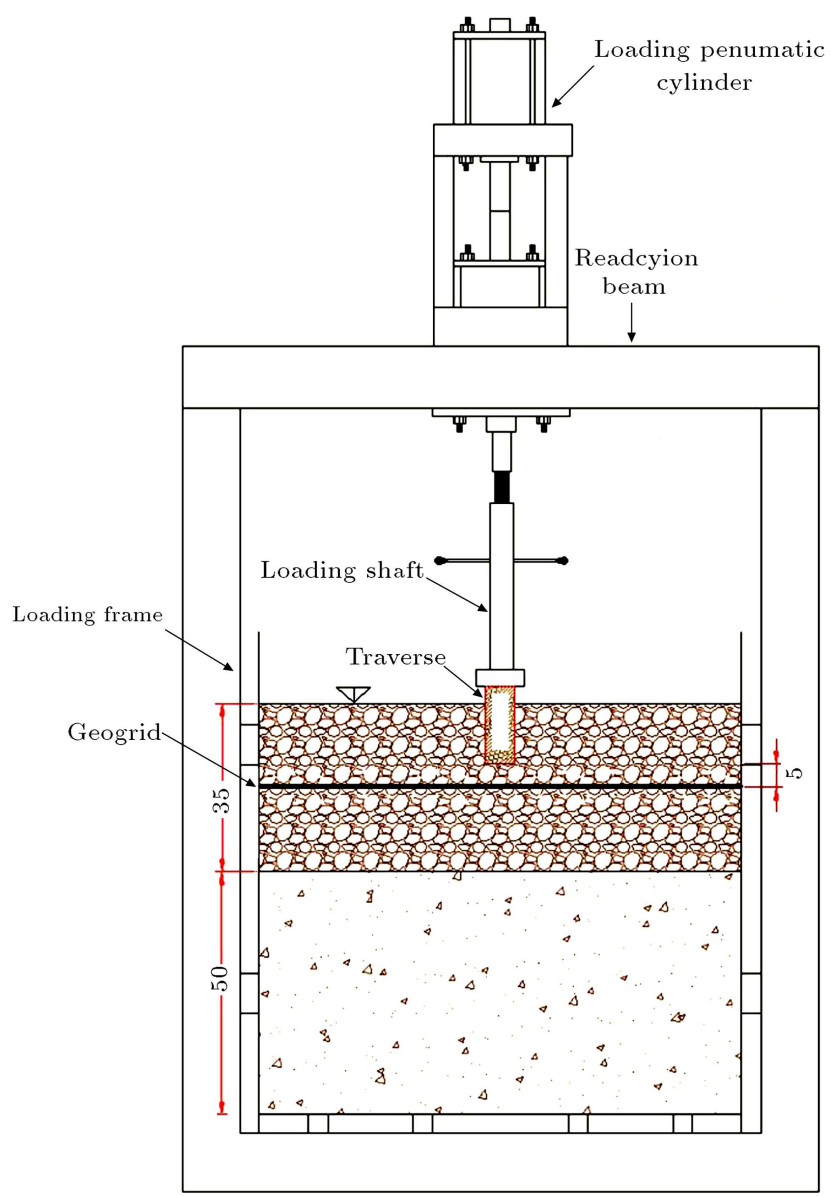

Figure 6. The schematic view of the testing device with one-layer geogrid.

repetition tests were done. After that, the tests were carried out in accordance with Table 3 .

In Table 3 , the first reinforcement layer $(u)$ and the distances of each layer $(d)$ are in terms of $\mathrm{cm}$.

\section{Results and discussions}

\subsection{The amount of traverse settlement under static and dynamic loads in the absence of geogrid}

After the compaction of $5 \mathrm{~cm}$ soil layer and the placing of the wooden traverse with the dimensions of $40 \times$ $16 \times 4 \mathrm{~cm}$, the static load of $295 \mathrm{kN} / \mathrm{m}^{2}$ and the dynamic loads with a frequency of 30 beats per minute were applied to traverse in the constant incremental steps. As indicated in Figure 7, the increase of the static load to $608 \%$ from $66.6 \mathrm{~kg}$ to $472 \mathrm{~kg}$ leads to an increase of $275 \%$ in the static settlement values from $0.04 \mathrm{~cm}$ to $0.15 \mathrm{~cm}$. Also, as shown in Figure 7 , the increase of the dynamic load up to $872 \mathrm{~kg}$ results in an increase of $35 \%(0.15$ to $0.2 \mathrm{~cm})$ in the dynamic settlement values. According to the tests conducted on the unreinforced ballast, an increase in the settlement was high at the beginning of loading, and the rate of 
Table 3. Details of experiments.

\begin{tabular}{|c|c|c|c|c|c|c|c|}
\hline $\begin{array}{c}\text { Type } \\
\text { of test }\end{array}$ & $\begin{array}{c}\text { Type of } \\
\text { reinforcement }\end{array}$ & $N$ & $\begin{array}{l}u / d \\
(\mathrm{~cm})\end{array}$ & $\begin{array}{c}\text { Max static } \\
\text { load }(\mathrm{kg})\end{array}$ & $\begin{array}{c}\text { Max dynamic } \\
\text { load (kg) }\end{array}$ & $\begin{array}{c}\text { Frequency } \\
\left(\mathbf{H z}_{\mathrm{z}}\right)\end{array}$ & $\begin{array}{c}\text { Number of } \\
\text { tests }\end{array}$ \\
\hline Unreinforced & - & - & - & 472 & 400 & 0.5 & 1 \\
\hline Reinforced & Geogrid & 1 & $10,15,20(u)$ & 472 & 400 & 0.5 & 3 \\
\hline Reinforced & Grid anchor & 1 & $5,10,15,20(u)$ & 472 & 400 & 0.5 & 4 \\
\hline Reinforced & Geogrid & 1 & $5(u)$ & 472 & 400 & $0.08,0.17,0.33,0.5$ & 4 \\
\hline Reinforced & Geogrid & 2,3 & $5(d)$ & 472 & 400 & 0.5 & 2 \\
\hline Reinforced & Geogrid & 4 & $5(d)$ & 472 & 1272 & 0.5 & 1 \\
\hline Reinforced & Geogrid & 4 & $5(d)$ & 472 & 400 & $0.08,0.17,0.33,0.5$ & 4 \\
\hline
\end{tabular}

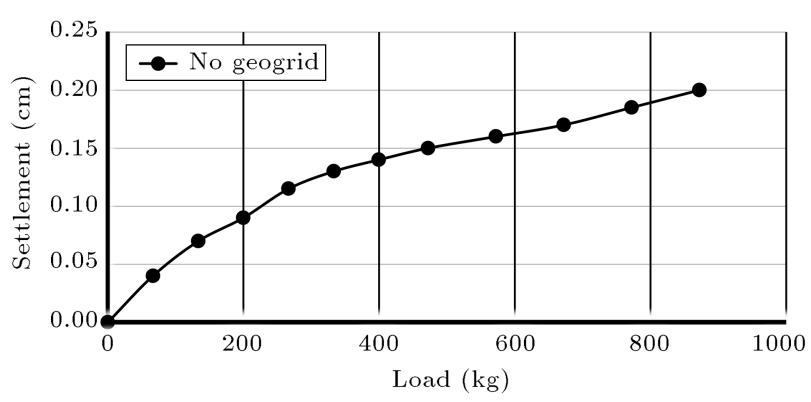

Figure 7. The amount of traverse settlement under static and dynamic loads in the absence of geogrid.

the ballast settlement tended to reduce with respect to an increase in loading value.

\subsection{The effect of one reinforcement layer on different depths with a constant frequency}

At this stage, to obtain the first optimal reinforcement layer, two series of experiments were conducted. The first series of tests was made by utilizing geogrid reinforcement, whereas the second series was performed by utilizing geogrid anchor reinforcements. Both tests were carried out under the dynamic load of $250 \mathrm{kN} / \mathrm{m}^{2}$ in the same conditions and the distances of $5,10,15$, and $20 \mathrm{~cm}$ from the traverse bottom.

\subsubsection{The effect of one geogrid layer}

The results of the tests performed on the ballast with one-layer geogrid are presented in Figure 8. As shown in the figure, the settlement rate increases as the geogrid distance increases to the traverse bottom, so that the $300 \%$ increase in the geogrid locations from the traverse bottom can cause an increase in soil settlement by $18 \%$. The increase of the static load to $608 \%$ leads to the increase of $275 \%$ in the static settlement rate. As seen in Figure 8, the optimal state lies at the distance of $5 \mathrm{~cm}$ from the traverse bottom. The $85 \%$ increase of the dynamic load from $472 \mathrm{~kg}$ to $872 \mathrm{~kg}$ results in a $14 \%$ increase in the settlement rate from 0.14 to $0.16 \mathrm{~cm}$. In this case, as compared with the absence of geogrid layer, the growth rate of settlement is reduced from $33 \%$ to $14 \%$.

This means that in addition to reducing the ballast settlement, the use of geogrid at a distance of

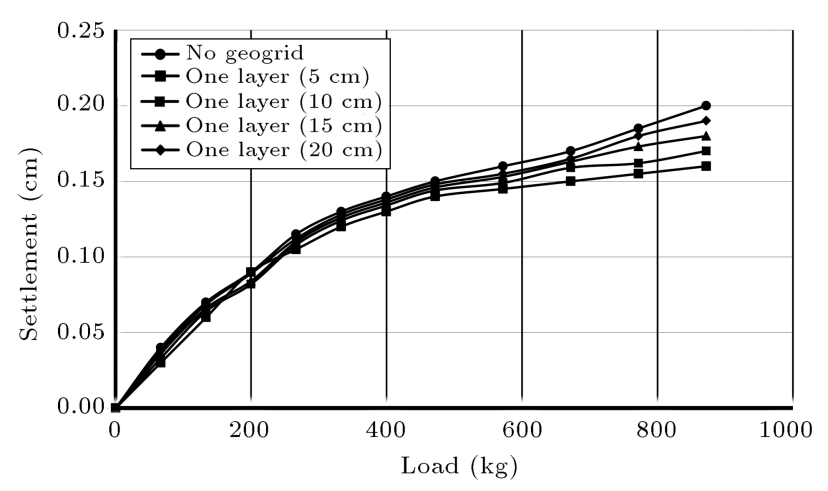

Figure 8. The effect of one-layer geogrid with various depths.

$5 \mathrm{~cm}$ from the traverse bottom leads to a reduction in the ballast settlement growth rate.

\subsubsection{The effect of one geogrid anchor layer}

In accordance with the tests performed on one-layer geogrid reinforcement, a few tests were done on ballast reinforced with one-layer geogrid anchor, and the effect of this kind of reinforcement was analyzed and compared with geogrid layer. The results are shown in Figure 9. As the location of the geogrid anchor to the traverse bottom increases, the settlement rate increases. So, the reinforcement distance increased to $300 \%$ from the traverse bottom, thereby increasing the settlement rate by $16.66 \%$. In the case that the ballast geogrid anchor layers were placed at the distance of

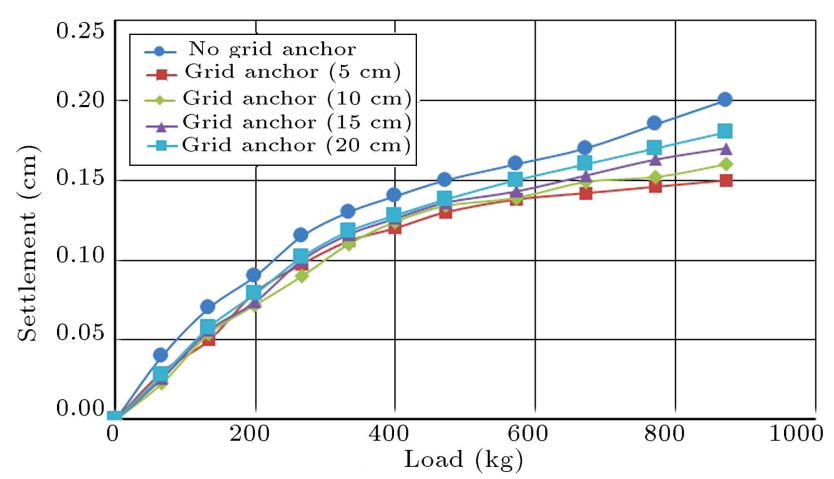

Figure 9. The effect of one-layer geogrid anchor with various depths. 
$5 \mathrm{~cm}$ from the traverse bottom, the settlement rate was reduced from $33 \%$ to $14 \%$. This means that in addition to reducing the ballast settlement, the use of the geogrid anchor at a distance of $5 \mathrm{~cm}$ from the traverse bottom leads to reducing the ballast settlement growth rate as well.

\subsection{The comparison of the geogrid and geogrid anchor in reducing the settlement}

The comparison of effects of geogrid anchor and geogrid layers on ballast settlement at 5, 10, 15, and $20 \mathrm{~cm}$ distance from the traverse bottom is shown in Figure 10. By using the geogrid anchor, the settlement rate was decreased to $6.25 \%, 5.88 \%, 5.55 \%$, and $5.25 \%$ as compared with the geogrid layer at the depth of $5 \mathrm{~cm}$ from traverse bottom. Therefore, the reinforcement efficiency in reducing settlement was relatively improved.

\subsection{The effect of one-layer geogrid with variable frequencies}

A number of tests were performed to investigate the load frequency effects on ballast behavior. In this case, all the parameters were fixed and the only variable was the frequency. The tests were done on one-layer geogrid at the distance of $5 \mathrm{~cm}$ from the traverse bottom. According to Figure 11, it can be concluded that reducing the amount of ballast dynamic load frequency reduces the settlement rate below the traverse so as to decrease the frequency from 30 to 5, 10, and 20 beats per minute, thereby reducing the traverse ballast

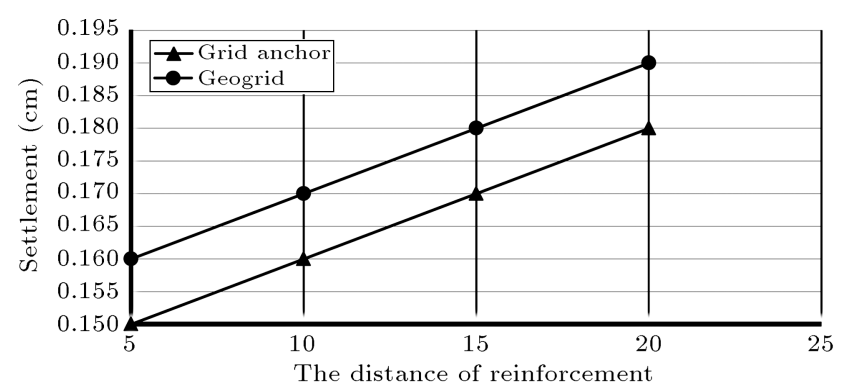

Figure 10. The comparison of the geogrid and geogrid anchor in settlement rate.

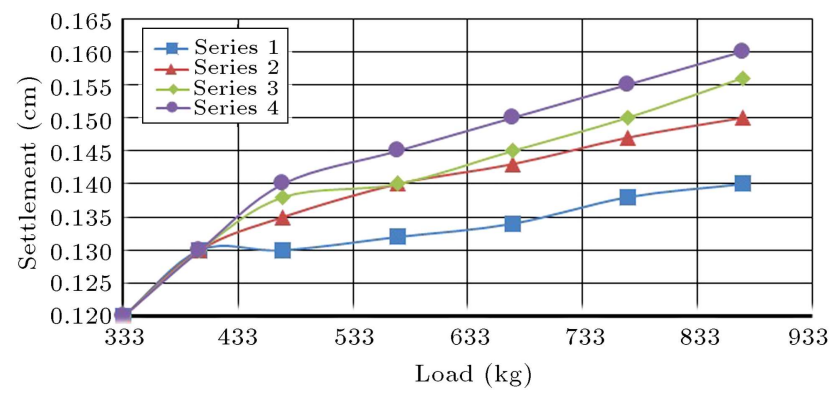

Figure 11. The settlement rate with one-layer geogrid by variable frequencies. dynamic settlement rate to $0.14,0.15$, and $0.156 \mathrm{~cm}$. In other words, by reducing the applied loading frequency to $83 \%, 16 \%$, and $33 \%$, the traverse settlement rate is decreased by $12.5 \%, 25.6 \%$, and $2.5 \%$.

\subsection{The effect of the geogrid layers}

In this section, it is assumed that all parameters remain constant. The effect of the geogrid layers was studied from 1 to 4 layers at the distance of $5 \mathrm{~cm}$ from each other, and the results are presented in Figure 12. By using four geogrid layers instead of one layer, a decrease in the corresponding settlement rate took place from 0.16 to $0.1 \mathrm{~cm}$. However, further increase in geogrid layers had slight effect on the decline of the ballast settlement rate. Alternatively, by using 3 geogrid layers, the settlement rate was perceptible. But, increasing the number of layers to 4 did not have significant influence on the final settlement.

Table 4 presents the ratio of $R_{S T}$ from one to four layers of reinforcement. As can be seen, $R_{S T} \max -$ imum effect was obtained for 4 reinforcement layers, indicating that the soil under the traverse was stiffened by adding the reinforcement layers and the stress distribution was increased under the traverse. Also, there was a slight difference between 4-layer and 3-layer $R_{S T}$. This indicates that more than 3 reinforcement layers have slight effect on the settlement reduction.

\subsection{The effect of the dynamic load amplitude with a constant frequency}

In this part, the effect of increasing the dynamic load amplitude was estimated on the optimal mode settlement rate with 4 reinforcement layers at the distances of $5 \mathrm{~cm}$. The dynamic load ratio was

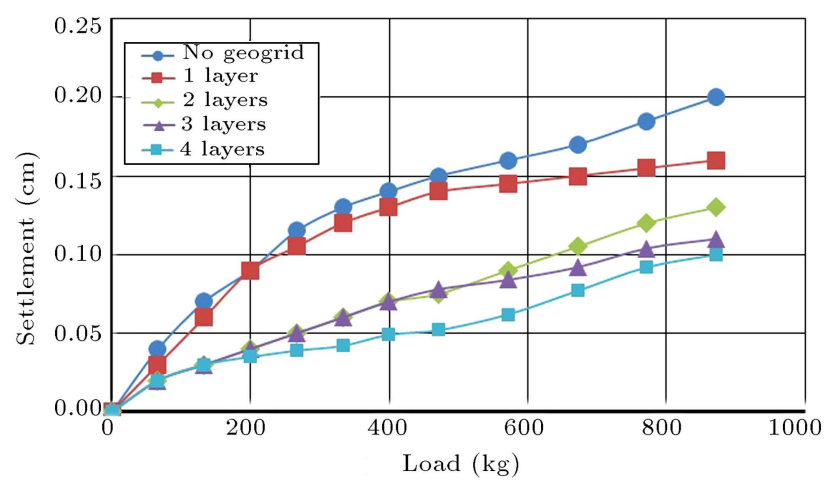

Figure 12. The effect of the geogrid layers.

Table 4. $R_{S T}$ with the addition of reinforcement layer.

\begin{tabular}{cc}
\hline Number of reinforcement & $\boldsymbol{R}_{\boldsymbol{s t}}(\boldsymbol{\%})$ \\
\hline 1 & 80 \\
2 & 65 \\
3 & 55 \\
4 & 50 \\
\hline
\end{tabular}




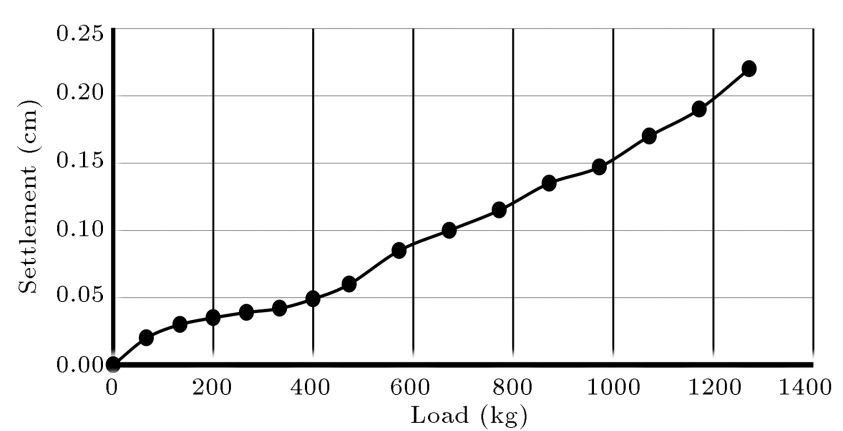

Figure 13. The ballast settlement rate under traverse with 4 geogrid layers by increasing $100 \%$ dynamic load.

increased to $25 \%, 50 \%, 75 \%$, and $200 \%$ of the specified load with loading frequency of 30 beats per minute. According to Figure 13, by increasing the dynamic load to $25 \%, 50 \%, 75 \%$, and $100 \%$, the settlement rate was increased by $30,70,100$, and $120 \%$, respectively. In other words, there was a direct relationship between the increase of the amount of load and the ballast settlement. Alternatively, by increasing the dynamic load, the settlement is also increased.

\subsection{The effect of the dynamic load amplitude with a variant frequency}

In this section, the effect of load frequency on the settlement was examined, and the results are presented in Figure 14. According to the figure, it can be concluded that by increasing the dynamic load frequency, the ballast settlement rate is increased so that the loading frequency can be increased from 2 to 5, 10, 20, and 30 beats per minute, thereby increasing the settlement rate from 0.62 to $0.72,0.83,0.092$, and $0.105 \mathrm{~cm}$.

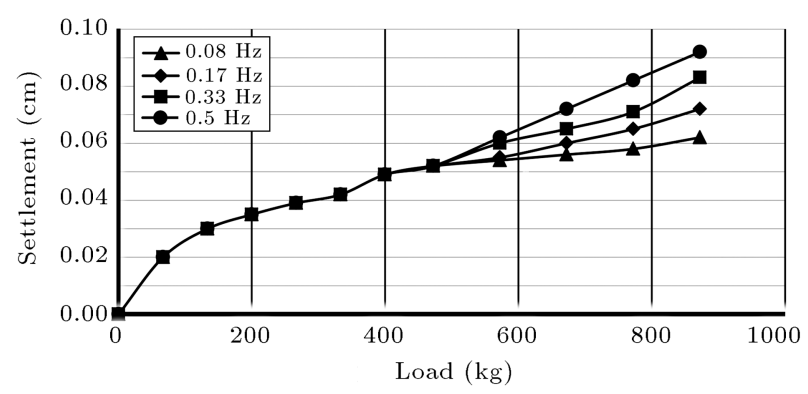

(a)

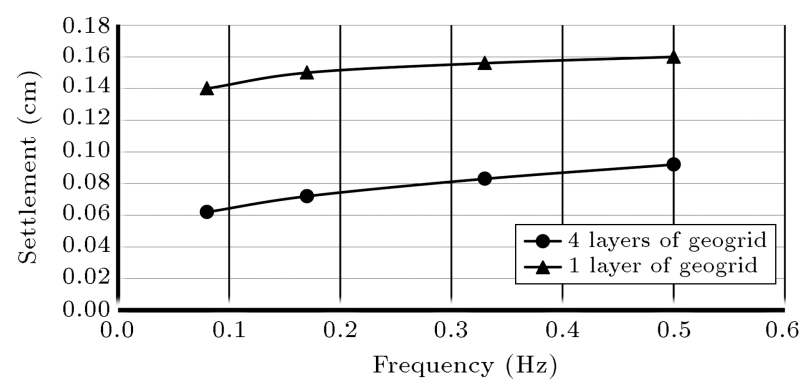

(b)

Figure 14. The effect of frequency on the ballast settlement rate.

\section{The relationship between the permanent settlement, the dynamic load, the frequency, and the reinforcement layers}

Based on the results of experiments, the following equations are presented to calculate the permanent settlement. Eq. (2) can calculate permanent settlement $\left(S_{t}\right)$ in terms of dynamic load amplitude $\left(q_{d}\right)$ :

$$
S_{t}=20 \times 10^{-7}\left(q_{d}\right)^{2}-0.003 q_{d}+0.2102 .
$$

Eq. (3) reveals the relationship between permanent settlement $\left(S_{t}\right)$, dynamic load amplitude $\left(q_{d}\right)$, and frequency of dynamic load $(f)$ :

$$
\begin{aligned}
\operatorname{Ln}\left(S_{t}\right)= & -7.756-0.0847 q_{d}+0.009 q_{d} \ln \left(q_{d}\right) \\
& +0.9\left(q_{d}\right)^{0.5}-\frac{0.05}{\ln (f)} .
\end{aligned}
$$

Eq. (4) shows the relationship between permanent settlement $\left(S_{t}\right)$, the dynamic load amplitude $\left(q_{d}\right)$, and the distance of one layer geogrid from the traverse bottom $(u)$ :

$$
\begin{aligned}
\operatorname{Ln}\left(S_{t}\right)= & -7.756-0.0847 q_{d}+0.009 q_{d} \ln \left(q_{d}\right) \\
& +0.9 q_{d}^{0.5}-\frac{0.05}{\ln (u)}
\end{aligned}
$$

At last, Eq. (5) can calculate permanent settlement $\left(S_{t}\right)$ in terms of the dynamic load amplitude $\left(q_{d}\right)$ and the number of geogrid layers $(N)$ :

$$
\begin{aligned}
S_{t}= & -0.0649-\frac{0.0197(N)}{\operatorname{Ln}(N)}+1.022 e^{-8} q_{d}^{2} \operatorname{Ln}\left(q_{d}\right) \\
& +0.0295 \operatorname{Ln}\left(q_{d}\right) .
\end{aligned}
$$

\section{Conclusion}

In this study, the effect of the geogrid and geogridanchor on reducing the ballast level settlement was considered. In this regard, through laboratory study (a small-scale test box), the behavior and ballast performance were simulated under field conditions in the presence of the reinforcement. In this experiment, by placing the geogrid and geogrid anchor layers, various factors, including the load frequency, the loading amplitude, the geogrid location, the number of geogrid layers, and their distances were investigated, and the related results were compared and analyzed. The summary of test results is as follows:

1. By increasing the geogrid location from the traverse bottom, the settlement is increased so that the maximum influence of geogrid at a distance of $5 \mathrm{~cm}$ from the bottom of the traverse can be observed; 
2. The settlement rate increases by increasing the dynamic load. This rate is higher at the beginning of the loading. At the end of the test, the increase rate of the ballast settlement is reduced;

3. By increasing the dynamic load by $85 \%$ (442 $\mathrm{kg}$ to $872 \mathrm{~kg}$ ), in the case of ballast with one-layer geogrid reinforcement which has been placed at a distance of $5 \mathrm{~cm}$ from the traverse bottom, the settlement rate is increased by $14 \%$ (from 0.14 to $0.16 \mathrm{~cm}$ );

4. By increasing the dynamic load amplitude, the settlement rate is increased. As an example, in the case of ballast reinforced with four-layer geogrid, by increasing the dynamic load amplitude by $200 \%$, the settlement increases from 0.11 to 0.22 ;

5. In the case of ballast reinforced with one-layer geogrid anchor placed at a distance of $5 \mathrm{~cm}$ from the traverse bottom by increasing the dynamic load up to $85 \%$, the settlement rate increases by $14 \%$ (from 0.13 to $0.11 \mathrm{~cm}$ ) as compared with the layer without the geogrid-anchor;

6. By increasing the number of geogrid layer, the settlement rate is decreased by $37.5 \%$. To illustrate this, by utilizing the four-layer geogrid in the range of $5 \mathrm{~cm}$, the settlement rate is decreased to $50 \%$. Hence, the best arrangement for the settlement decrease is the four-layer one. Nonetheless, by using up to 3-layer geogrid, an increase in the number of geogrid layers is highly perceptible to decrease the ballast settlement;

7. By using the geogrid anchor, the settlement rate was decreased up to $6.25 \%$ to compare with the geogrid layer. Therefore, the grid anchor was more effective than geogrid in decreasing traverse settlement.

\section{References}

1. Yeo, B., Yen, S.C., Puri, V.K., Das, B.M. and Wright, M.A.A. "Laboratory investigation into the settlement of a foundation on geogrid-reinforced sand due to cyclic load", Geotechnical and Geological Engineering, 11, pp. 1-14 (1993).

2. Das, B.M. and Shin, E.C. "Strip foundation on geogrid-reinforced clay: Behaviour under cyclic loading", Geotextile and Geomembranes, 13, pp. 657-667 (1994).

3. Das, B.M. and Shin, E.C. "Laboratory model tests for cyclic load-induced settlement of a strip foundation clayey soil", Geotechnical and Geological Engineering, 14(3), pp. 213-225 (1996).

4. Ling, H.I. and Liu, Z. "Performance of geosyntheticreinforced asphalt pavements", Journal of Geothechnical and Geoenvironmental Engineering, 127(2), pp. 177-184 (2001).
5. Nazzal, N., Farsakhr, M. and Mohamad, L. "Laboratory characterization of reinforced crushed limestone under monotonic and cyclic loading", Journal of $M a$ terials in Civil Engineering, pp. 772-784 (2007).

6. Claus, H. and Ulrike, C. Weisemann, "Effectiveness of a reinforcing geogrid in a railwaysubbase under dynamic loads", Geotextile and Geomembranes, pp. 254-259 (1994).

7. Das, B.M., Shin, E.C. and Kim, D.H. "Geogridreinforced railroad bed settlement due to cyclic load", Geotechnical and Geological Engineering, 20, pp. 261271 (2002).

8. Brown, S.F., Kwan, J. and Thom, N.H. "Identifying the key parameters that influence geogrid reinforcement of railway ballast", Geotextiles and Geomembranes, 35, pp. 326-335 (2007).

9. Boushehrian, A.H., Hataf, N. and Ghahramani, A. "Modeling of the cyclic behavior of shallow foundations resting on geomesh and grid-anchor reinforced sand", Geotextile and Geomembranes, pp. 1-7 (2010).

10. MoghaddasTafreshi, S.N. and Khalaj, O. "Laboratory tests of small-diameter HDPE pipes buried in reinforced sand under repeat-load", Geotextiles and Geomembranes, pp. 145-163 (2008).

11. MoghaddasTafreshi, S.N. and Khalaj, O. "Analysis of repeat laboratory tests on buried plastic pipes in sand", Soil Dynamic and Earthquake Engineering, 31, pp. 1-15 (2010)

12. Das, B.M. and Maji, A. "Transient loading-related settlement of a square foundation on geogrid-reinforced sand", Geotechnical and Geological Engineering, 12, pp. 241-251 (1994).

13. Ghosh, A. and Bera, A. "Bearing capacity of square footing on pond ash reinforced with jute-geotextile", Geotextiles and Geomembranes, 23, pp. 144-173 (2005).

14. Demerchant, M.R., Valsangkar, A.J. and Schriver, A.B. "Plate load tests on geogrid-reinforced expanded shale lightweight aggregate", Geotextiles and Geomembranes, 20, pp. 173-190 (2003).

15. Kumar Dash, S., Sireesh, S. and Sitharam, T.G. "Model studies on circular footing supported on geocell reinforced sand underlain by soft clay", Geotextiles and Geomembranes, 21, pp. 197-219 (2003).

16. Boushehrian, A.H. and Hataf, N. "Bearing capacity of ring footings on reinforced clay", The 12th International Conference of International Association for Computer Methods and Advances in Geomechanics (IACMAG), pp. 1-8 (2008). 
17. Patra, C.R., Das, B.M. and Atalar, C. "Bearing capacity of embedded strip foundation on geogrid reinforced sand", Geotextiles and Geomembranes, 22, pp. 454-462 (2005).

18. Patra, C.R., Das, B.M., Bhoil, M. and Shin, E.C. "Eccentrically loaded strip foundation on geogridreinforced sand", Geotextiles and Geomembranes, pp. 254-259 (2006).

19. Sitharam, T.G. and Sireesh, S. "Effects of base geogrid on geocell-reinforced foundation beds", Geotextiles and Geoengineering: An International Journal, 1(3), pp. 207-216 (2006).

20. Won Yoon, Y. and Seong Kang, D. "Bearing capacity and settlement of tire-reinforced sands", Geotextiles and Geomembranes, 22, pp. 439-453 (2004).

21. Boushehrian, A.H., Hataf, N. and Ghahramani, A. "Experimental and numerical behavior of shallow foundations on sand reinforced with geogrid and grid anchor under cyclic loading", Scientia Iranica, 17(1), pp. 1-10 (2010).

22. Mosallanezhad, M., Hatef, N. and Ghahramani, A. "Experimental study of bearing capacity of granular soils, reinforced with innovative gride-anchore system", Geotechnical and Geologicla Engineering, 25(1), pp. 123-137 (2007).

23. Christakos, G. "Soil behaviour under dynamic loading conditions: experimental procedures and statistical trends", Stochastic Environmental Research and Risk Assessment, 17(3), pp. 175-190 (2003).

24. Tafreshi, S.N. and Dawson, A.R. "Behaviour of footings on reinforced sand subject to repeat loadingcomparing use of 3D and planar geotextile", Geotextiles and Gomembranes, 28(5), pp. 434-447 (2010).

25. MoghaddasTafreshi, S.N., Khalag, O., Dawson, A.R. and Masek, B. "Repeated load response of soil reinforced by two layers of Geocell", Procedia Earth and Planetary Science, 15, pp. 99-104 (2015).
26. No. 301, General Specifications of Ballasted Railway tracks, State Management and Planning Organization, Iran (2004).

\section{Biographies}

Alireza HajianiBoushehrian received his BSc degree in Civil Engineering from Persian Gulf University in 2002. He also received his $\mathrm{MSc}$ and $\mathrm{PhD}$ degrees in Civil Engineering (Soil Mechanics and Foundations) from Shiraz University, Iran, in 2004 and 2010, respectively. He is now an Assistant Professor in Department of Civil Engineering, School of Engineering, Islamic Azad University of Shiraz. He has participated in writing and reviewing a number of papers published in refereed journals and conference proceedings in the reinforced soil and foundation engineering. His research interests are dynamic and cyclic experimental modelings, dam en gineering, and numerical methods.

Arash Vafamand received his BSc degree in Civil Engineering from Estahban Islamic Azad University, Iran, in 2010. He was accepted for MSc degree in 2010. His field of study was Soil Dynamics and Cycling Modeling. He attended the 2nd International Conference on Traditional Knowledge for Water Resources Management and presented some parts of his thesis. He received his MSc degree from Najaf Abad Islamic Azad University in 2013.

Saeed Kohan received the Master of Science of Highway Engineering from Payame Noor University, International Center of Asaluyeh, Iran, in 2014. His research interests are dynamic modeling and railway ballast behavior. 